\title{
Building the evidence base for macro-systemic change
} or...creating the bookmark of the future

\author{
Jim Ridgway \\ School of Education, University of Durham, Leazes Road \\ Durham DHI ITA, England. \\ Jim.Ridgway@Durham.ac.uk
}

\begin{abstract}
The theme of Chile 2000 is 'The bookmark of the school of the future'. This paper sets out ways to develop the content of the bookmarked sites. A global trend can be detected towards evidence-based policy and practice. There is a great deal of evidence on exciting ideas concerning the application of ICT in education, but rather little in the way of structured critique of this evidence. ICT faces two major challenges; first, the need to assemble existing evidence in a way that is accessible to users; second, to develop working methods that are appropriate in fields that are not only changing very rapidly, but which are also changing in radical ways. The challenge of creating the contents of the 'bookmark of the school of the future' in the face of macro-systemic change is the focus of this paper.
\end{abstract}

Keywords: Systems; macro-systemic change; assessment; vision; evidence based policy and practice; the meta-generation.

\section{INTRODUCTION}

It is notoriously difficult to bring about desirable changes in educational practice, even when the desired changes are to shift the centre of gravity of the bulk of educational practice towards the existing practices of a significant number of excellent teachers. ICT poses problems which are qualitatively more difficult. New educational goals are radically different to old ones, and the base of craft skills on which to build is very modest. The problem is exacerbated because new technologies with exciting educational potentials continue to emerge, and so educational reform must continually

The original version of this chapter was revised: The copyright line was incorrect. This has been corrected. The Erratum to this chapter is available at DOI: 10.1007/978-0-387-35403-3_29 
address new challenges. These new challenges require a novel approach to the creation and utilisation of knowledge; existing paradigms are not appropriate for a climate of rapid change. The chapter sets out some ideas on appropriate ways to create and use new knowledge under these circumstances of rapid intellectual change. This requires an analysis of current approaches to change, with some critical analysis of the strengths and weaknesses of these approaches, and an account of ways in which an evolving evidence base can be constructed. A goal of the paper is to go well beyond an overview of key concepts and themes on ways to make good uses of emerging technologies. It sets out first to problematise these themes, and then to argue for a different style of knowledge creation and utilisation. The valuable contributions from the IFIP community need to be presented in a variety of ways for a variety of audiences if they are to become useful to a broader educational community. The paper begins with a brief account of global trends which influence education obliquely, then an account of the global trends which influence education directly. The conference theme is 'The bookmark of the school of the future', and so it is important to ask about the content of the URLs that the bookmark points to. As well as considering the contents of the URLs, it is essential to consider the ways that the evidence to be presented in these URLs is created, critiqued, and displayed. The paper concludes with a review of the challenges and opportunities that ICT offers for further research.

\section{GLOBAL TRENDS}

This section sets out to identify some global trends, in order to contextualise work in education.

Evidence based policy and practice. In fields such as medicine, there has been a dramatic movement away from a dependence on the wisdom and craft skills of local experts towards the use of large scale literature reviews of effective practice, which are then embedded into local practice and national policy. In the political arena, one can identify trends away from politics towards a technology of improved social functioning. Central issues of public concern, such as health, crime, poverty and economic well-being are addressed by looking for methods that are effective, rather than by assuming that the answers to these problems can be deduced from political principles of either the political right ('get the economy in good shape, and everything else follows'), or the political left ('address the problems of social justice, and everything else follows'). A major lesson from these trends is that both politicians and practitioners are likely to demand high quality evidence on which to base their decisions. 
Accountability. Accountability is now a major theme in all areas of professional practice (e.g. Moonen, 2000). This theme can be seen in the increased use of statistical data to account for the performance of governments, and government agencies - such as those concerned with health and crime. In education, it is reflected in practices such as the publication of 'league tables' of the performance of schools and school districts. League tables are only possible if one has a single measure of performance. The development of a single measure of complex performance requires value judgements on how qualitatively different aspects of performance (such as cognitive gain, emotional development, social functioning) should be weighted (Rapley and Ridgway, 1998; Moonen, 2000). A major lesson from this trend is that, without considerable work, agents in educational systems are likely to be judged on an increasingly narrow set of performance measures - notably those associated with conventional academic performance. A key activity for the IFIP community must be to design measures of attainment which relate to new educational goals. Without them, new educational ambitions are likely to be ignored.

Shared rhetoric on education. An interesting development world-wide has been the emergence of a shared set of educational goals. These can be observed in the similarities of statements related to National Curricula or their equivalents from different countries, and the statements of educational aims from government ministers around the world. Curriculum ambitions can be summarised (with heroic brevity). There will be an increased emphasis on mathematics and sciences. Within these subjects, there will be an increased emphasis on problem solving, and communication skills, with a focus on solving practical problems. Global political rhetoric can also be summarised (again, heroically). Low-skill, high-wage economies (such as those associated with car production during the 1950 s, for example) can no longer be sustained in a global economy where capital (and jobs) is easy to shift from country to country. Economic success will depend on a 'knowledge economy' where high wage economies depend on high skill levels, and on 'adding value'. Education must respond in three distinct ways. First, students must be equipped with high-level intellectual skills, in order to contribute to the new knowledge economy. Second, they must be aware of the complexity of acting and making decisions in a complex and changing world, in order that they cope personally with a fast changing environment, and in order that they are 'informed citizens' functioning in a democratic society. Third, there must be a provision to support life-long learning.

An increased focus on education. Governments are aware increasingly of the importance of education to economic performance. However, the education community should not be complacent about this increasing 
political focus on education. It is worth remembering the adage 'War is too important to be left to the generals'. By analogy, as politicians attach greater value to education, they are also less likely to allow important decisions on the practice of education to be left in the hands of educators. If the educational community is to retain some autonomy in this critical arena of national policy, there is a need to demonstrate professional expertise. Developing an evidence base for policy and practice is an essential component in demonstrating expertise.

Academic capitalism. There is an emerging body of evidence tracking changes in the ways that knowledge is created and used (e.g. Slaughter and Leslie, 1997). Universities are less dominant in the creation of new knowledge than before; corporations increasingly are devoting considerable resources to basic research as well as to product-oriented research. Industryacademic links are being fostered, as the emergence of on-campus Science Parks testify. Internationally recognised qualifications are being created, such as Microsoft certification of the ability to use different software products. Courses are being franchised internationally, and accredited world-wide. Universities are forming alliances globally to collaborate on teaching, and to recognise courses as being equivalent. Non-traditional providers are entering the educational arena. These trends show that the whole area of education is in flux; old assumptions and values are undergoing revision. Of particular note is the emergence of assessments based on competencies defined by commercial demands, and possible conflicting views of the ownership of knowledge. Traditionally, universities have focussed on the creation and free dissemination of knowledge throughout the academic community. Such approaches are alien to commercial practice, where knowledge is guarded jealously. These trends towards academic capitalism contradict many of the ambitions expressed in this volume, such as the desire for education tailored to local circumstances and needs, and open access to knowledge.

\section{THE NEW INTELLECTUAL AGENDA}

A number of important themes have been developed throughout this volume. The emergence of a consensus on educational goals from papers written independently around the world is exciting, and evidence that the new vision is clear and appropriate. However, in the implementation of any new vision, one must work out what can go wrong, and plan appropriately. This section sets out to problematise some of the visions presented earlier.

A clear theme in this volume is that students will no longer be the passive recipients of other people's knowledge. The new educational agenda 
requires students to gather evidence, to evaluate the quality of that evidence, and to interpret it in new ways. This requires considerable intellectual sophistication. In particular, it requires: the development of metaknowledge, that is to say, knowledge about knowledge creation and use; the acceptance that knowledge exists only in relation to some purpose and not in any absolute sense; and an acceptance of constructivism as a philosophical stance (Azinian (2000); Collis (2000); Downes and Zammit (2000); Fagundes (2000); Isaac (2000); Jansen, Fisser and Terluw (2000); Midoro (2000); Nikolova (2000); Passig (2000); Schubert (2000); and Westbroek (2000)). While these ideas reflect much current thinking in education, they are not shared universally, nor is it clear that they are easily acquired.

From product to process. Educational reforms in mathematics in the USA provide some evidence on the difficulties of shifting the balance of educational activities from an emphasis on technique to a balance of activities where mathematical processes. notably problem solving and communication skills, play an important role. Despite extensive consultation and consensus building on the nature of mathematical reforms across all manner of stakeholder groups, there has been a back-lash from conservative university professors of mathematics, who advocate 'back-to-basics' mathematics. Congressional Hearings are now taking place in the USA to investigate the educational validity of current reformed curricula.

From truth to relativism. Another lesson from reforms in the USA is the emergence of the religious right as a significant reactionary force. Here, the thrust of the resistance is that to teach problem-solving is to corrupt young people. If students are taught to examine evidence critically, to create multiple interpretations and multiple solutions to complex problems, they are likely to generalise this to their religious beliefs. Received wisdom will be challenged, and students might no longer accept scripture as absolute truth.

Even without this radical critique of new educational ambitions, there may be considerable problems in promoting relativism. A study conducted in the 1960s (Perry, 1970) on undergraduates studying humanities at Harvard and Radcliffe College illustrates these challenges. Perry tracked the intellectual development of students via a series of interviews, and identified a number of stages of intellectual development. Many students entered college with a view that knowledge existed in an absolute sense - things are either true, or not true. When this standpoint broke down, it was replaced by a nihilistic (postmodern?) stance, where any theory was viewed as the equivalent of any other theory. At a later stage of development, for some but not all students, a relativist position emerged; rival accounts can be judged against each other in terms of their power to account for the available evidence. Perry's study suggests that current ambitions to develop metaknowledge in school may be too optimistic. The emergence of a nihilistic 
phase may pose extreme problems for classroom management. As a counter argument, one might argue that few attempts have been made to develop a relativistic approach. Competent use of the new technologies requires this intellectual development, which may occur seamlessly.

Promoting meta-knowledge. A number of authors emphasise the importance of the development of metacognitive knowledge. These include self-monitoring skills, and self-knowledge. Developing these skills may well be difficult; studies of expert-novice differences (e.g. Schoenfeld, 1985) suggest that the time line for the development of metacognitive knowledge is likely to be decades rather than years. However, this evidence is based on earlier, pre-ICT based learning activities in schools; it may well be the case that metacognitive knowledge can be developed far more quickly, once it is taken seriously as an educational goal (e.g. Adey and Shayer (1994).

Modelling via new representations and symbol systems. A number of contributors argue for the development of the ability to work with new representations and symbol systems. Schubert (2000), for example, argues that modelling will become increasingly important as the use of ICT grows. Existing evidence from international surveys (e.g. TIMSS: http:/www.csteep.bc.edu/timss) shows that students find it very difficult to solve problems which require abstract representations (such as the use of algebra). It is to be hoped that students exposed to ICT-rich curricula will perform better than their predecessors.

Modelling complex processes and problems. This challenge takes students to the forefront of academic work. Almost by definition, developing the skills to model complex processes such as those associated with society and our environment are likely to be difficult.

Learning to know; to do; to live together; to be. Both Cornu and Danon (2000) and Machado (2000) discussed the Report of the International Commission on Education presented in the Delors Report (1996) to UNESCO. These important ideas draw attention to the need for education to go way beyond the development of cognitive skills. Delors, and many contributors to this volume, argue for an educational focus on the development of ethics and morality; a knowledge of self, and the role of the individual in society; and the responsibility that different societies have towards each other. It should be remembered that this vision of the functions of education is not shared, universally. Margaret Thatcher famously once stated that 'there is no such thing as society'. While educators might have no sympathy for such views, they illustrate the need for those concerned with innovation to have a clear view of the wide range of beliefs about the nature and functions of education.

Despite the cautionary tone of this Section, a general conclusion can be drawn that ICT poses a major challenge to current accounts of human 
development. Learning environments can be created which are qualitatively different from earlier learning environments, and old theories might not be robust in these new settings. There are exciting challenges to revisit major theories of development of knowledge in all of its forms.

\section{EVIDENCE AND MODELS}

The major focus of this paper is to explore ways in which an evidence base can be developed which will support the introduction of different and more appropriate educational practices. This section explores the nature of evidence, and some styles of modelling.

\subsection{Evidence based policy and practice}

The conference title is 'The Bookmark of the School of the Future'. This title contains an implicit challenge to the IFIP community to explore ways in which knowledge can be presented in a way that is useful to a variety of users. Examination of the emergence of evidence based practice (EBPP) in other areas - notably medicine - provides a useful starting point.

The Cochrane Collaboration is an international network comprising 15 Centres in 11 countries. Their work is published in the Cochrane Library and several other forms. For example, Bandolier (www.jr2.ox.ac.uk/Bandolier) is updated monthly, and is designed to bring evidence to a wide range of health professionals. The website receives 40,000 hits per week. Issues might relate to the effectiveness of particular drugs, of some surgical procedure, or of a clinical approach such as screening for cancers of different sort. All members of the collaboration aim to discover all the evidence available, and to summarise it (for example by calculating the effect size of a treatment, based on a meta-analysis of every available study). Results are then made public. Tight criteria are set in order to decide which studies can be included in the analyses. In the case of studies on the effectiveness of a particular drug, for example, only controlled randomised trials (CRTs) are considered. Dissemination of results takes place in two distinct ways; first via publication in leading medical journals, and second via the web. Web sites are designed to encourage comment and challenges to the comprehensiveness of the literature surveyed, to the methods used, and to the interpretation of the analyses. A similar approach is needed to support professionals in education. The work of the Cochrane collaboration has been sketched here as an excellent example of an approach 
to EBPP. However, as a model to support EBPP for the school of the future, it has serious limitations, some of which are set out below.

\subsection{Kinds of evidence}

Before setting out an agenda for building the evidence base to support new educational ambitions, it will be worthwhile characterising the status of different sorts of evidence. For any topic, evidence can be available in a number of forms, which have different status and power for EBPP. For example, one can consider:

Phenomena. Evidence at the level of phenomenon describes things which happened in particular circumstances, on a particular occasion (which might extend over years). Case studies are examples of such knowledge (see Azinian (2000) and Westbroek (2000) for school development case histories). This sort of evidence can provide insight and can be a rich source of speculation about the generality of the observation to other situations. Alone, descriptions of phenomena are unlikely to provide reliable guides to future practice.

Regularities. Regularities correspond to the idea of 'laws' in physics; they are empirical generalisations which have been observed on a number of occasions, and which suggest some causal links between action and outcome. Regularities can often be expressed in the form: 'when you do $<\mathrm{A}>$, then $<\mathrm{B}>$ happens'. Meta-analyses of drug trials provide an example of this sort of evidence.

Models. Models can take a variety of forms, and can include fullyfledged theoretical accounts. In the sense used here, a model is a description of the topic of interest (a particular learner, or a whole school, for example) together with a set of regularities, integrated in such a way as to provide guidance on the most likely effective practice.

Using different kinds of evidence. Phenomena, regularities and models have different status in terms of their usefulness to bookmark users. Phenomena provide a stimulus to thought; the more similar the background circumstances of the example given to those of the bookmark user, then the more likely the description is to be of value in guiding practice. Regularities are likely to be of use when simple decisions are to be made about how to act; models will be essential in planning action is situations where a number of interacting variables are involved. 


\subsection{Styles of modelling}

Modelling is an essential component of every scientific enterprise, and a wide variety of styles of modelling are used in different scientific disciplines. It is appropriate, therefore, to consider different styles of modelling, in order to choose a style that matches the challenges posed by ICT in education.

A model is any kind of representation of a situation. Mathematical models are common. There, some aspect of the world is coded into a mathematical formalism; the formalism is manipulated to draw some conclusions, which are then decoded back from the mathematics into the situation in the real setting which is of interest. It is most important that the model captures the essence of the situation of interest. Consider this mathematics problem: King Henry VIII had 6 wives. How many wives had King Henry IV?

The humour comes from the fact that an inappropriate mathematical model is implicit in the question. The example illustrates a key point in modelling, namely that the formalism must represent the essential elements of the situation being modelled. The sorts of educational reforms associated with ICT have a number of characteristics that make them particularly difficult to model. These challenges are addressed later in the paper. To explore the challenges, it is essential to consider different approaches to modelling. Only a brief description can be given here; a fuller account can be found in Ridgway (1998).

Analytic modelling. Analytic modelling is common in school physics. The approach is to tackle a complex problem by breaking it down into simpler parts, and studying each part in turn. The parts are then reassembled, to create a model of the whole situation. This approach is extremely powerful in situations where variables can be manipulated independently, and where there is little or no feedback between variables.

Systemic modelling. Here, the challenge is to model situations where elements interact. Systemic modelling requires a careful description of all the elements in the sy'stem, and a specification of the links between each of the elements. It is a powerful approach for dealing with complex situations where the overall system stays the same, despite dramatic shifts in the values of individual parameters.

Macro-systemic modelling. Some systems change radically over time. Consider the Earth in space. Initially, a cloud of gas cooled to a liquid state, then to a solid state. Water formed on the surface. This created conditions in which life could emerge. One particular life form made use of photosynthesis - whose by-product is oxygen. As a result, the atmosphere of the planet changed to become oxygen rich. This new system made it 
possible for new life forms to exist, which depend on oxygen for their survival. To describe the history of the world, it is not enough to talk about an evolving system; the world has undergone radical, qualitative changes the gas cloud, the molten ball, the solid with surface water, the system containing photosynthesising plants, and the current biosphere, are quite unlike each other, in system terms. This shift from system to system is referred to here as macro-systemic change. The characteristics of macrosystemic change are that some changes take place which make other changes possible. In turn, these make yet further changes possible, and the system undergoes change of such a radical nature that it becomes a new system.

Consider an example of macro-systemic change driven by technology. In 1902, there was no powered flight. In 1914, aeroplanes were being used in warfare. In 1945, a single aeroplane was instrumental in ending a world war. In 2000, delegates fly to Chile from all over the world to discuss the impact of technology on education. This example shows that technology has a radical impact on patterns of human activity. A technological change makes certain things possible. Some of these happen, and a new system emerges. The new system makes other things possible, and so on. Current social systems are qualitatively different from those that existed a few decades ago, and many of these differences have been brought about by technological changes. The example also shows that macro-systemic change can occur very rapidly. References to features of macro-systemic change can be found in Machado (2000) and in Saldano and Reyes (2000).

Different modelling styles are not tied to specific disciplines. Most disciplines use most styles of modelling; some examples are shown below.

Table 1: Modelling styles in education and ecology

\begin{tabular}{|c|c|c|c|}
\hline & $\begin{array}{c}\text { Analytic } \\
\text { (c.f. school physics) }\end{array}$ & $\begin{array}{c}\text { Systemic } \\
\text { (c.f. school } \\
\text { biology) }\end{array}$ & $\begin{array}{c}\text { Macro-systemic } \\
\text { (c.f. evolution) }\end{array}$ \\
\hline Education & $\begin{array}{c}\text { Skinnerian } \\
\text { conditioning }\end{array}$ & $\begin{array}{c}\text { models of } \\
\text { memory }\end{array}$ & $\begin{array}{c}\text { Piagetian and } \\
\text { Vygotskian cognitive } \\
\text { development }\end{array}$ \\
\hline Ecology & field trials & $\begin{array}{c}\text { predator-prey } \\
\text { relations }\end{array}$ & ecology changes \\
\hline
\end{tabular}

Some sorts of macro-systemic change are predictable. The life cycle of the frog or the butterfly provide examples. In some educational settings, the same thing is likely to be true. The development of ICT based education in 
schools with similar characteristics may well follow a similar course (see Ridgway and Passey, 1995). Other sorts of macro-systemic changes are unpredictable. Neither the emergence of the web nor its social impact was predictable in advance. The example of the social impact of aeroplanes provides a further example. Predictable and unpredictable macro-systemic change pose somewhat different challenges to educational innovation.

\section{BUILDING THE EVIDENCE BASE}

How might an evidence base be constructed? The core challenge is to design patterns of knowledge creation and knowledge use which are relevant in the context of macro-systemic change. The first subsection considers ways to make effective use of current knowledge; the second section sets out some principles of research applicable to situations characterised by macrosystemic change.

ICT in education is bringing about macro-systemic change. Collis (2000), for example, describes educational activities that were simply not possible 20 years ago; Passey (2000) describes patterns of home-school working that are impossible without ICT. The IFIP community needs to consider ways in which an evidence base can be built up which will support the educational community. One way to begin is too consider the working methods of other academic communities which engage in macro-systemic change. Ecological restoration will be used as an example.

\subsection{Macro-systemic change in relatively stable worlds}

One example of ecological restoration is provided by attempts to return land that has been used for agriculture to its pre-agricultural state; as in prairie restoration. The methods used are described in detail elsewhere (Murray, 1993; Ridgway, 1998); the principles, and the lessons for education, are set out here.

Vision. Ecological restoration needs a clear vision of what is to be attained; this has direct analogies with education (see Collis (2000); Hylen (2000); Isaac (2000); Machado (2000); Maturana and Cabezon (2000); Nikolova (2000); Passig (2000); Saldano and Reyes (2000); Schubert (2000); Westbroek (2000)).

Rich and accurate descriptions. Ecologists have a wealth of rich descriptions about individual plants and environments, and about the match between plant and environment. There is also extensive knowledge about entire environments, which include information not just about plants which 
are found together, but also about pollinating insects, and other features of the ecology. Tools are available for assessing the health of plants, and appropriate ways exist to remedy failure to thrive. There is a good deal of knowledge about the sorts of plants that are easy to grow, the timelines for growth, and the life cycle.

There is an extensive body of knowledge on the possible transitions from one system state to another. For example, to create a spruce wood from two radically different starting points (say, rock and pond) different transitions are required, as follows:

- rock to lichen to meadow to aspens to spruce;

- $\quad$ pond to marsh to meadow to aspens to spruce.

The knowledge base can serve a number of different functions:

- identifying conditions favourable to certain kinds of communities;

- planning desirable changes;

- implementing desirable changes;

- monitoring on-going changes.

Analogies with education demand that we assemble the following information:

- detailed descriptions of different sorts of student attainment

- descriptions of different ICT activities - which should specify what the activities do NOT include - (see Jansen, Fisser and Terlouw, 2000); Kassam, 2000), and which should include a statement of prerequisites (such as teacher and student competencies, and resource needs)

- knowledge of ICT activities that are common (and easy to establish), and which are rare (and perhaps harder to establish)

- knowledge of the relative effects of different ICT activities in terms of their learning outcomes

- ability to recognise inappropriate activities, and to remedy them

- descriptions of different types of community (or systems) - ways in which classrooms, schools, neighbourhoods, school districts and states can be classified in terms of local circumstances, and in terms of ICT use

- knowledge of transition states, e.g. as ICT is introduced into a school.

\subsubsection{Understanding systems and system dynamics}

A key focus is to understand the dynamics of individual systems. (see Marshall, 2000; Nikolova, 2000; and Westbroek, 2000). In the case of education, there needs to be a clear specification of the elements in a system (political will; curriculum definitions; assessment systems; patterns of professional development; teacher competencies; community conceptions, and the like) and an account of how change can be engineered within such systems. For example, changes in political will are unlikely to have any 
effect unless teacher skills are developed; curriculum changes are unlikely to occur unless assessment systems are redesigned so as to reward teachers and schools for achieving new educational goals (Ridgway, 1998).

\subsubsection{Understanding macro-systemic change in stable settings}

Beyond these understandings of system dynamics, there needs to be an account of ways that the transitions between systems can be achieved. In the case of school reform, other schools can provide examples of plausible stages of development and transition states (Ridgway and Passey, 1995). In the case of large scale systems - at school district or state level, for example - studies of analogous systems undergoing change can provide models.

There is an extensive body of knowledge in the ICT community that can be used to begin to build this evidence base. A key to this development is to discover regularities across systems in terms of the key elements, and to look for regularities in terms of the transitions form one system to another.

\subsection{Macro-systemic change in unstable worlds}

The problems of macro-systemic change in unstable settings need not just better descriptions and mappings, but also some new approaches to research. There is a need to conduct research at the leading edge of change, in order to explore the 'art of the possible'. Such work complements studies on the integration of innovative practices into the main stream of the curriculum. This section suggests appropriate research strategies.

Exploring affordances. The whole purpose of leading edge research is to explore possible educational activities. These cannot be known in advance. Researchers have a responsibility to explore the range of opportunities that new developments allow, and can support. Part of this work must be the gathering of evidence in such a way as to persuade a reasonable sceptic, rather than to inspire acolytes.

Fail forwards. In any innovative arena, it is important to take the steep learning curve seriously. This requires an appropriate mind - set towards failure. Small failures, blind alleys, and wasted effort are an essential component of successful work. Counting on success and punishing failure is in inappropriate strategy. The exploratory style, appropriate to innovate arenas, is summarised in a variety of different mantra, which include 'fail forwards'; 'ready, fire, aim'; and 'fail fast, and fail often'. Fortune and Peters (1995), and Marshall (2000) provide some examples of the lessons that can be learned from failures, and point to the mind-set which chooses to ignore studies of failure. 
Cybernetic feedback. I use the term 'cybernetic feedback' to refer to a practice of using feedback to actively steer the course of future work. Conventionally, feedback is used to ensure that work is on target, and as the basis for small changes. Cybernetic feedback is different in the important respect that it is used to set new targets. Once one discovers that certain desirable things are made possible by new developments, they become educational goals.

Fast dissemination. A key element of working with macro-systemic change in unstable areas is the need to need to establish systems for the fast dissemination of results, in a form which is useable by different groups.

\section{CENTRES FOR EVIDENCE BASED POLICY AND PRACTICE}

Centres are needed which can be visited regularly by users. There are few problems in principle with establishing such sites, given the number of existing sites designed to provide some sort of support for users (for example, Enlaces in Chile; the National Grid for Learning in the UK; the European Schoolnet (EUN) and its partner networks; EducaDi in Brazil; Kenniset in the Netherlands; Interactive Education Strategies for Schools in New Zealand; EuMedia, supporting professional development in Europe), but a great deal of thought needs to be given the nature of information that is provided at these sites, and the ways this information might be made use of. As in the case of EBPP in medicine, the user must be in no doubt about the knowledge claims being made. The sources of evidence, and the routes to access original sources, must be made clear. This section will consider some of the challenges which EBPP faces, and some of the ways that these challenges might be met.

Communicating with users. There are major problems associated with communicating new ideas. All constructivist accounts argue that one sees the world through the lenses of existing knowledge structures. Communication about novel practices, therefore runs real risks that genuine novelty will be 'adapted' (in the Piagetian sense) to existing knowledge structures. Serious attention must be paid to studies of the ways that users interact with information on EBPP (Downes and Zammit, 2000).

Vivid exemplification of processes and goals. A response to this challenge is to ensure that vivid descriptions of phenomena and effects be provided (in the form, for example, of annotated video clips of learning activities, and assessment schemes with annotated student work). Graf and Yokochi (2000) provide an example which goes some way to satisfying this demand. 
Quality assurance: countering dilution and corruption. A classic problem with innovation is that initial exemplary practice drifts back to the banal. Users need ways (and encouragement) to check the fidelity of practices at regular intervals. Issues of the quality of learning activities are paramount (e.g. Collis, 2000; Machado, 2000). Useless activities need identification (such as unfocussed browsing; or use of dubious sites (Collis, 2000); inappropriate patterns of communication between students (Graf and Yokichi, 2000).

Distinguishing evidence and theory. Evidence should be kept distinct from theoretical claims (as far as this is possible), to facilitate later reconceptualisations.

Claims on effect size. Effect sizes in education are likely to vary considerably across settings. Even when the overall effect of some treatment is large, there will be schools and classroom that show no gains (e.g. Ridgway, Zawojewski and Hoover (in press)). Politically, at both local and higher levels, this is important; some stakeholders are likely to form a negative view of new practices. It may well be the case that the less sympathetic stakeholders are likely to implement sub-optimal treatments, and suffer weak gains, thus reinforcing their original resistance.

\subsection{Conceptualising systems and macro-systems}

This is an area where users will need support. Tools for system descriptions are needed, and some are already available . Further, the whole notion of how users set about conceptualising and modelling systems (e.g. Saldano and Reyes, 2000; Azinian, 2000), and conceptualising macrosystemic change (Fagundes, 2000) will need to be explored.

Critiquing plans. There is a need for tools which support users at an early stage of planning. Systems problems should be considered very early on in planning. Some examples are included below; other examples can be found elsewhere (e.g. Checkland, 1981).

Generalisation. Can the practice the user has in mind be generalised beyond the settings in which it has been demonstrated to be effective? A classic failure of planning is to believe that the results from a specially funded project based on highly motivated volunteers with special skills who work far too hard, can be generalised across the education system.

System capacity. Is there capacity within the system to allow a particular sort of practice? For example, it was clear from the outset that LOGO required high levels of teacher preparation, and long periods of time in class with students working in small groups on computers. In most educational settings, these issues of system capacity should rule it out as a sensible educational innovation. 
Parameter estimation. It is important to estimate the time lines for change; the effect sizes for different treatments; and costs. These data are available in the ICT community ('it takes about 10 days of professional development to enable teachers to use $<x>$ fluently in class'). These data need to be accessible at the Centre. It is clear that educational benefits are multidimensional, not unidimensional, (Moonen, 2000) and any review of evidence will need to describe attainment along a number of dimensions.

Predicting unexpected outcomes. This apparent paradox can be resolved via both 'what if' analyses, and by fast feedback from early implementation. The likely implications of particular changes can be thought through in advance. Discovering the emerging impacts of new approaches should be a component of the 'fail fast, fail often' research strategy. Examples from the conference include: the accelerated asset stripping of expertise from poor countries by rich countries (Isaac, 2000); support provided for extreme political views (Kassam, 2000; Lai, 2000); dangers that new technologies will lead to increased social exclusion (Fagundes; 2000); and schools getting bigger or smaller (Hylen, 2000).

Challenging the status of 'academic' knowledge. An implication of EBPP is the challenge it poses to conventional notions of knowledge. The craft skills of 'educational engineering' will become far more salient to users than high level theoretical accounts. It is most important that theoreticians stay engaged with these processes of reform; criticism and reflection must be a characteristic of future work. The co-emergence of a strong evidence base linked directly to conceptual analyses, is likely to accelerate progress in both practical and theoretical domains.

\section{CONCLUSIONS}

The school of the future, as now, will be a complex system located in a local, national and global system. There is a need for a continuous process of addressing systems issues, and issues of macro-systemic change.

\section{Practical Urgencies}

- There is a need for visions of possible, desirable futures

- Centres for Evidence Based Practice which explore user uses, and which support all user communities should be created, or built on existing sites

- New educational goals require vivid exemplification, via appropriate assessment tools, descriptions of intellectual processes, and examples of student work

- New educational practices require robust quality assurance systems 


\section{Theoretical Urgencies}

- Educational engineering is at least as important as theory; its status should be raised

- A new science of change is needed, urgently

- Knowledge creation and implementation need to be better understood In order to create 'the meta generation', there is a need to review a number of existing areas, in the light of the impact of ICT on learning. These include:

- the development of ideas about knowledge

- cognitive development

- the development of metacognition

- the development of morality and ethical behaviour

- New sorts of mental processes become important as ICT is used. There is a need to explore the development these 'new intelligences'.

\section{REFERENCES}

Adey P. and Shayer, M. (1994) Really Raising Standards: cognitive intervention and academic achievement. London:Routledge.

Azinian, H. (2000) Dissemination of ICT and change in school culture. This volume.

Checkland, P. (1981) Systems Thinking, Systems Practice. New York: Wiley.

Collis, B. (2000) The school of the future: The WWW and learning processes/ new learning environments. This volume.

Cornu, B and Danon, C. (2000) Didactics, Information and Communication Technologies, and the Teacher of the Future. This volume.

Delors, J. et al (1996) Education Holds a Treasure. Report of the International Commission on Education for the Twenty-First Century. UNESCO:HMSO/UNESCO Publications.

Downes, T and Zammit, K. (2000) New literacies for connected learning in global classrooms. This volume.

Fagundes, L. (2000) Assisting or creating the future? This volume.

Fortune, J., and Peters, G. (1995) Learning from Failure: the Systems Approach. New York: Wiley.

Graf, K.-D. and Yokochi, K. (2000) Students teach students in telecommunications. This volume.

Isaac, J. (2000) Identifying educational core competencies for the Information Age: Towards conscious transformation from data to knowledge, This volume.

Jansen, P., Fisser, P., and Terlouw, C. (2000) Designing digital learning environments. This volume.

Kassam, A. (2000) Networked technologies and other stories: New paradigms for learning. This volume.

Machado, A. (2000) Current Status and Perspectives for Education in Latin America. This volume.

Marshall, G. (2000) Exquisite complexity: Rethinking the learning process and learning environment in the Information Age. This volume. 
Maturana, H. and Cabezon, E. (2000) Values and competencies in the school of the future. This volume.

Midoro, V. (2000) How teachers and teacher training are changing. This volume.

Moonen, J. (2000) Return-on-Investment and On-line Learning. This volume.

Murray, M. (1993) Prairie restoration for Wisconsin schools. University of WisconsinMadison Arboretum: Madison.

Nikolova, I. (2000) Teacher development in ICT: Vision and implementation. This volume.

Passig, D. (2000) Taxonomy of IT mediate future thinking skills. This volume

Perry, W. (1970) Intellectual and Ethical Development in the College Years. Holt: New York.

Rapley, M., and Ridgway, J. (1998) "Quality of Life" Talk and the corporatisation of intellectual disability. Disability \& Society, 13, 3, 451-471.

Ridgway, J. (1998) From Barrier to Lever: Revising Roles for Assessment in Mathematics Education. National Institute for Science Education Brief. pp. 8.

Ridgway, J. (1998) The Modelling of Systems and Macro-Systemic Change - Lessons for Evaluation from Epidemiology and Ecology. National Institute for Science Education Monograph 8. University of Wisconsin-Madison.

Ridgway, J., and Passey, D. (1995) Integrating IT: How to Use Existing Evidence About Individual Teacher Evolution to Plan Systemic Revolution. In D. Tinsley and D. Watson (eds.). Integrating Information Technology into Education. London: Blackwell. pp 59-72.

Ridgway, J., Zawojewski, J., and Hoover, M. (2000, in press) Problematising Evidence Based Policy and Practice. Evaluation and Research in Education.

Saldano, A. and Reyes, M. (2000) Edunetmatics, education assisted by world telematic net. This volume.

Schoenfeld, A. (1985) Mathematical problem solving. Orlando, FL: Academic Press.

Schubert, S. (2000) The impact of modelling in education of informatics on collaborative learning with school Intranets. This volume.

Slaughter, S. and Leslie, L. (1997) Academic Capitalism: Politics, Policies and the Entrepreneurial University. Baltimore MD: Johns Hopkins University Press.

Westbroek, J. (2000) The Esloo design for digital elementary and secondary education. This volume.

\section{BIOGRAPHY}

James Ridgway is professor of education at the University of Durham. $\mathrm{He}$ is an applied psychologist whose interests include: educational uses of ICT; assessment; and educational change. When at Lancaster University, he was Director of the Centre for the Study of Advanced Learning Technologies, an inter-departmental research group, and Director of STAC, a project devoted to supporting the use of technology across the school curriculum. Currently, he directs a project developing ICT-based assessment of problem solving for high attaining students, and is a director of the Mathematics Assessment Resource Service (a major project funded by NSF in the USA) which provides practical support to States, Cities and Districts on all aspects of assessment. 